\title{
Artigos
}

Ana Katia Alves dos Santos'

\section{A emergência da criança como sujeito de direitos na Educação Infantil}

Resumo: O presente texto objetiva apresentar as reflexões sistematizadas pós realização de curso de extensão (ACCS - Atividade Curricular em Comunidade e Sociedade) de nome'Infância e Juventude: Ética da preservação humana, cidadania e educação no século XXI com código EDCH 072, na Faculdade de Educação da Universidade Federal da Bahia, bem como contou com a contribuição atualizada, de professores em formação no componente curricular de código EDC308 de temática relacional. O eixo central é a emergência da Criança como Sujeito de Direitos na Educação Infantil a partir do reconhecimento da necessidade de implantação efetiva do Estatuto da Criança e do Adolescente (ECA) e outros instrumentos legais relativos a garantia de direito ao grupo infantil. Na busca por aprofundamento, e alcance de respostas, a metodologia fundante é de natureza qualitativa com técnica grupo focal. A base teórica se sustenta em RAYO (2004), SANTOS (2006), MARCílIO (1998), JARES (2002) dentre outros.

Palavras-chave: Criança como sujeito de direitos. Educação Infantil. Formação de Professores.

\section{Child emergency as a subject of rights in Child Education}

Abstract: The present text has the objective of presenting systematized reflections after completion of an extension course (ACCS - Curricular Activity in Community and Society) named 'Childhood and Youth: Ethics of human preservation, citizenship and education in the 21st century with EDCH code 072, In the Faculty of Education of the Federal University of Bahia, and counted on the updated contribution, in 2017, of teachers in formation in the curricular component of EDC308 code of relational thematic. The central theme is the emergence of the Child as a Rights Subject in Early Childhood Education, based on the recognition of the need to effectively implement the Child and Adolescent Statute (ECA) and other legal instruments related to guaranteeing the rights of children. In the search for deepening, and reaching answers, the founding methodology is of a qualitative nature with focal group technique. The theoretical basis is based on RAYO (2004), SANTOS (2006), MARCílIO (1998), JARES (2002) among others.

Keywords: Child as subject of rights. Childeducation. Teacher training.

' Doutora em Educação pela Universidade Federal da Bahia. Professora na Universidade Federal da Bahia. E-mail: aksantos@ufba.br 


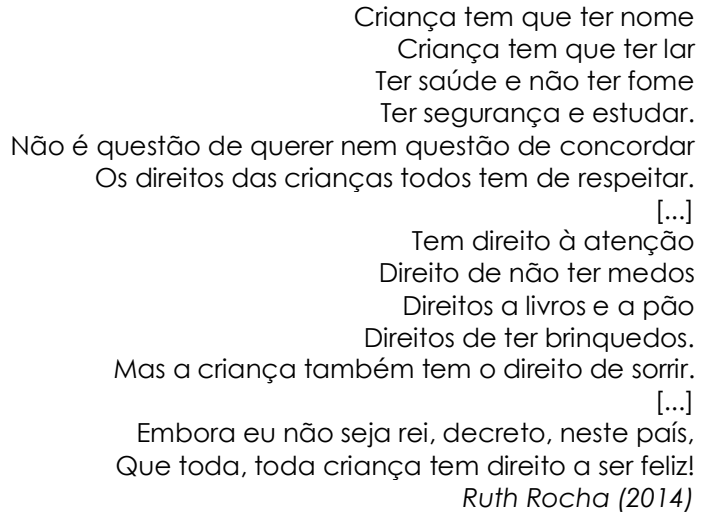

\section{Introdução}

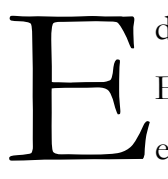

de fato, e de direito, possível considerar a emergência da criança como sujeito de direitos na Educação Infantil Brasileira? Estaríamos nós, professores/pedagogos preparados para proteger e garantir, no contexto da prática político-pedagógica da escola infantil, a proteção e a defesa de direitos plenos que a estas crianças a legislação no Brasil garante, em especial o Estatuto da Criança e do Adolescente, mas conhecido como ECA? Em que medida, nós professores, poderíamos contribuir para a efetiva validação do ECA no contexto da Educação Infantil?

É certo que, esse debate exige tanto ação política quanto formação de pensamento filosóficoepistemológico com elaboração de uma concepção atualizada acerca da criança. Para isso, pode-se identificar argumentos, que surgiram do ponto de vista empírico, a partir do que Regine Sirota (2011) chama de contexto 'microssociológico', este que parte das interações entre adultos e crianças, com destaque para o âmbito das instituições infantis, estas que recebem influências diretas dos movimentos sociais externos.

As reflexões sistematizadas neste texto, são fruto de resultados alcançados pós realização da atividade de extensão de nome 'Infância e Juventude: Ética da preservação humana, cidadania e educação no século XXI' (2015/2016) objeto da proposta de curso de extensão (ACCS - Atividade Curricular em Comunidade e Sociedade) com código EDCH 072, na Faculdade de Educação da Universidade Federal da Bahia, bem como contou com a contribuição atualizada em 2017 de professores em formação no componente curricular de código EDC308 de temática relacional.

A metodologia de pesquisa foi de natureza Qualitativa (ANDRÈ, 2005), esta que leva em conta a interpretação dos significados contidos no texto e falas dos participantes e as suas inter-relações, preocupando-se com o estudo dos fenômenos humanos e sociais a fim de compreendê-los e interpretálos. Utilizou-se como técnica o Grupo Focal que é comprometido, também, com a interpretação dos fatos e fenômenos através do diálogo e das discussões viabilizadas por ele, sendo, portanto, de abordagem compreensivista dialógica.

Esta pesquisa, então, foi sistematizada no primeiro semestre de 2016, tendo como lócus/ campo o Centro Integrado de Apoio a Criança e Adolescente (CIAC) localizado em área de situação de risco de 
Salvador. O CIAC acolhe 80 crianças, distribuídas em dois turnos e a sua população é de maioria negra (média de 85\%). Demos especial atenção ao contato direto com educadores sociais e estudantes em formação pedagógica que lidam com as crianças de menor idade (até os 6 anos). Participaram da pesquisa, dezoito estudantes de pedagogia e sete 'educadores sociais', onde se encontraram em grupos focais quinzenais, num total de seis encontros, com tempo de duas horas a cada encontro a fim de refletirem sobre a obrigatoriedade da implantação nas escolas brasileiras, e em especial como estavam validando o ECA na própria instituição.

Parte desses nossos estudos foi apresentada no III Seminário Luso-Brasileiro de Educação de Infância, que ocorreu na Universidade Federal de Alagoas em julho de 2017.

\section{O estatuto da Criança e do Adolescente e a emergência da criança como sujeito de direitos na Educação Infantil}

Um dos pontos de reflexão que surgiu durante a pesquisa, nos fez concluir que o ECA ainda não foi implantando de forma efetiva nas instituições de educação infantil no Brasil, nota-se pelas precárias condições materiais e formativas a que estão submetidas as crianças, bem como há ainda muito que ser feito para que as mesmas sejam, de fato, considerada 'sujeitos de direitos', esta que é uma categoria a ser largamente construída, principalmente pelos adultos que lidam e transitam pelo universo infantil, neste caso professores e demais profissionais da educação.

Sobre este aspecto, em um dos momentos do grupo focal foi lançada a seguinte questão problematizadora: Qual a relação entre Educação Infantil e Estatuto da Criança e do Adolescente? questão esta que suscitou as reflexões a seguir:

\footnotetext{
professor X: Na minha opinião a Educação de crianças e o Estatuto da Criança e do Adolescente se dá de forma dicotômica. Uma deveria conversar melhor com a outra, onde o Estatuto traz os direitos e os deveres da criança o que deveria contribuir com a sua educaşão.

professor Y: A relação entre eles se dá de forma distante e próxima ao mesmo tempo, já que o Estatuto assegura o direito aos estudos, enquanto a Educação na maioria das vezes quando fornecida é precária. Não sendo assistido o que necessariamente é prometido pelo Estatuto.

professor K: A educação infantil deve garantir e orientar a todos acerca dos direitos da criança [...] por meio dela se organiza a sociedade.

professor $W: A$ lei protege integralmente [...] a criança conforme o ECA e a Educação de crianças também deveria ser protegida, pois toda criança tem direito ao estudo.

professor Z:as crianças têm o direito a educação, mas nem sempre é assim. Então os movimentos sociais que muito significativamente vieram a colaborar para que estes pequenos seres humanos tivessem seus direitos garantidos foi necessário se estabelecer um documento oficial que desse conta destes direitos. Era necessário que as crianças [...] tivessem o direito a vo\%:
}

Um ponto subsequente de reflexão, nos fez investigar, então, a trajetória da construção de uma 'nova' categoria ou seja, a criança como sujeito de direitos! Categoria necessária para dar sustentação ao projeto político-pedagógico das escolas de educação infantil. Afinal, o que sabemos sobre o percurso histórico relativos a documentos legais que contribuem com a construção da criança como sujeito de direitos? Como podemos validar direitos e garantir qualidade de vida escolar às crianças se não 
conhecemos as bases da lei (ECA) que sustentam a vida dessa geração e o 'movimento social' que a impulsionou? Como os adultos que participam da vida infantil, podem contribuir efetivamente para a garantia dos seus direitos, fortalecendo a emergência da criança como sujeito de direitos?

A provocação acerca da emergência dessa categoria, nos fez dialogar com aos professores sobre o que eles entendiam por 'Criança como Sujeito de Direitos'. Surgiram, então, respostas que nos mobilizaram a seguir aprofundando o tema.

Professor A: É uma criança com direito a vida, ao amor de sua família, a saúde, educação de boa qualidade, a moradia. Ser reconbecida como um ser social dotado de direitos e tê-los garantidos. Pois, infelizmente existem as leis, mas não existia a fiscalização efetiva que as garante.

Professor B: É criança que deve ser respeitada e considerada em suas características peculiares, segundo cada idade e necessidade correspondente. Não um adulto mirim ou um ser insignificante, que não pensa, analisa, participa, interage.

Professor C: Todo ser humano tem direitos garantidos por lei, a crianca por estar em fase de desenvolvimento tem direitos específicos, [...] contudo não deixa de fazer parte dos outros direitos a que todos têm garantidos na constituição, embora muitos direitos não são cumpridos pelo Estado.

Professor D: É a criança que deve ter liberdade de se expressar, transmitir o que sente, através de suas emoções [...] devemos olhar a criança como sujeito de direitos e não como seres incapažes, mas como seres que trazem a capacidade de interagir e produzir conbecimento.

Professor F: É a criança que tem direito a brincar, a saúde, a educação, a proteção dos pais, ao laz̧er, a alimentação. Esses direitos devem ser garantidos pelos pais e pelo Estado.

Para aprofundamento desse estudo, resgatamos o capítulo I da obra de Santos (2006) quando trata da trajetória história na elaboração de instrumentos legais úteis para a construção dessa 'nova' categoria e concepção de criança como sujeito de direitos. As contribuições de Maria Luiza Marcílio (1998) foram, também, fundamentais para esta elaboração epistemológico-reflexiva com vista à construção desse conceito. Para isto fez-se preciso fazer a distinção da natureza entre o ECA (paradigma da Proteção Integral) e o antigo código de menores (Lei 6697/79) este que foi a reformulação do conhecido Código Mello Mattos, de 12 de outubro de 1927, Decreto n 17.943 ou paradigma da Situação Irregular do Menor, que tinha como um dos maiores fundamentos o binômio assistencialismo-vigilância.

Figura 1: Destaque para dois Instrumentos legais de base para visões de infância no Brasil

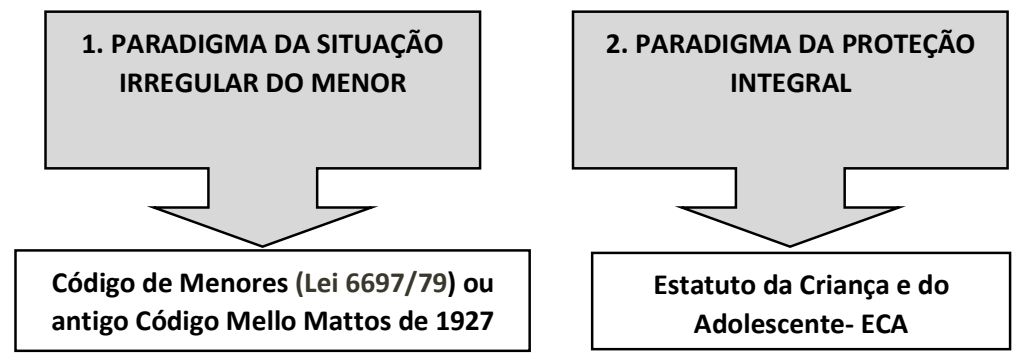

Fonte: Figura elaborada pela autora.

Sobre este binômio, foi também, inicialmente sustentada a escola de educação infantil e creches brasileiras (com destaque para o paradigma 1). Nota-se que, segundo Fuly et al (2012, p 87) 
Com a grande urbanização brasileira, surge um problema grave a ser resolvido: muitas eram as crianças abandonadas. Surge então, em 1832 no Rio de Janeiro, a primeira instituição de amparo a crianças abandonadas, conhecida no Brasil como "roda do exposto ou do enjeitado", com a real intenção de esconder a vergonha da mãe solteira. As crianças eram sempre filhas de mulheres da corte, pois somente essas tinham do que se envergonhar e motivo para se descartar do filho indesejado; as pobres precisavam de seus filhos para ajudar no trabalho, e dos filhos das escravas precisavam os senhores abastados. (RIZZO, 2010, p. 37). Ao todo foram treze rodas pelo Brasil, comumente nos grandes centros. As crianças que ali chegavam normalmente já estavam bastante debilitadas em razão da distância percorrida e condições de viagem. Com todo esse percurso assistencialista se deu a criação das creches brasileiras (grifo nosso). Não há de se negar que as "instituições de caridade", que assumiam essas crianças pequenas na ausência de suas mães, ministravam algum tipo de educação às mesmas, porém tratava-se de uma instrução não pautada em currículo ou planejada com os devidos cuidados pedagógicos, pois ora tendia ao treinamento para o trabalho, ora para o, também treinamento, das primeiras letras, sempre com o intuito de prepará-las para a vida como adultos em miniaturas.

A visão assistencialista, na sociedade de forma geral, e na Educação Infantil e creches brasileiras, perdura até aproximadamente a década de 90 do século passado, somente a partir daí, com a sistematização de instrumentos legais, a saber o Estatuto da Criança e do Adolescente (1990), a Lei de Diretrizes e Bases da Educação Nacional, os Referenciais Curriculares da Educação Infantil (1998) e mais recentemente as Diretrizes Curriculares da Educação(2010) a concepção vai sendo modificada.

Essas modificações, partem da mudança de perspectiva e paradigma. O antigo 'código de menores' conceituava a criança como menor ou infância menorizada. Esta que, como retrata a citação de Luzy acima, é a abandonada ou em situação irregular! Não se olhava para a criança como um todo, muito menos preocupa-se com a sua proteção e garantia de direitos plenos. A preocupação era a de vigiar e manter a 'teórica' sobrevivência às crianças consideradas 'inadaptadas sociais'. O código de menores preocupa-se com o conflito social instalado desde o início do século XX, e não com a prevenção, educação, garantia de direitos e reintegração social das crianças!

Era um modelo cristalizado de infância que dura até meados do século XX. As palavras criança e menor tinham duas conotações: a primeira, segundo Didonet et al (2011, p.18), "[...] Era a branca, bem nutrida, de sorriso cativante, filha de família de classe média e alta, cujo futuro poderia ser previsto como bem-estar, desenvolvimento e felicidade". Já a segunda (menor) era associada a

[...] criança negra, desnutrida, de família pobre ou desestruturada, altamente vulnerável à doença e candidata a engrossar a estatística da mortalidade infantil ou, se sobrevivesse, a marginalizar-se e tornar-se um risco social; ou seja, o filho do proprietário (colonizador, descendente de europeu, branco) tornou-se "criança", enquanto o filho do despossuído (negro, descendente de escravo, pobre) tornou-se "menor" (Didonet, 2011, p. 18)

Óbvio que este paradigma, que conceituava a criança como menor, sofreu críticas severas à forma como concebia e tratava a criança de modo geral, sendo substituído por uma outra possibilidade que considerava medidas protetivas, de inclusão e de garantia de direitos para todas indistintamente.

O paradigma da proteção integral, base para o ECA, e para a construção de uma nova 'categoria' social de criança como sujeito de direitos, considera que a família, o Estado e a Sociedade devem prover, proteger e garantir direitos para uma vida infantil digna e plena. O ECA é uma política de atendimento que articula deveres e direitos e que vislumbra o alcance do desenvolvimento pessoal e social da criança e 
do adolescente, situando-os como cidadãos plenos. $\mathrm{O}$ mesmo considera que a proteção à criança é Prioridade absoluta! Nesse sentido, a atenção prioritária deve ser dada também à educação infantil, vislumbrando a qualificação desse nível de ensino para o atendimento pleno e protetor.

Como afirmamos antes, Santos (2006) e Maria Luíza Marcílio (1998) apresentam o histórico que fundamentou essa atual 'categoria' e concepção de criança: O movimento de emancipação do homem e da mulher em contexto moderno, nos séculos XVII e XVIII, formularam os instrumentos legais dos Direitos Naturais do Homem e do Cidadão. Recentemente em final do século XX e início do XXI, o direito ao desenvolvimento, ao meio ambiente, à paz, à democracia e o direito dos consumidores destacam-se, bem como o direito à democracia é condição fundamental para a concretização dos Direitos Humanos. Em 1948, a Declaração Universal dos Direitos Humanos (dentre outros instrumentos legais), desenvolve as bases para a ampla garantia de direitos à 'todos os seres humanos'. O direito à cidadania e a participação integral da criança, da mulher e do homem à sociedade tornam-se eixo de defesa. Vide figura a seguir:

Figura 1: Instrumentos Legais de Direitos Humanos que inclui a criança.

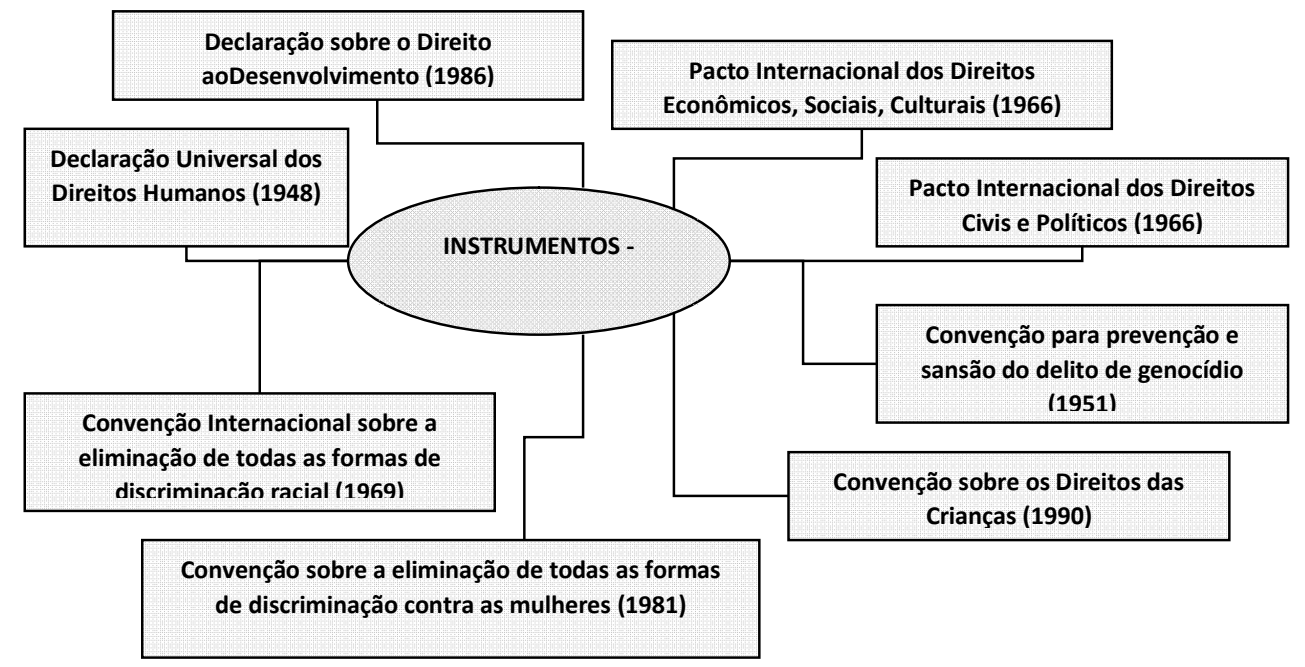

Fonte: Figura elaborada pela autora.

A infância, a partir da formulação desses instrumentos legais, em percurso histórico, vai sendo valorizada em suas especificidades. Dessa forma, destaca-se que a elaboração de direitos específicos para as crianças, compreendidos como especiais, torna-se importante e inclui desde 1923 os princípios gerais dos direitos das crianças que foram defendidos pela organização não-governamental International Union for ChildWelfare. Marcílio (1998) aprofunda que, em 1924, a Liga das Nações, reunida em Genebra, assumiu também esses princípios e apresentou-os na primeira Declaração dos Direitos da Criança. O primeiro princípio, desta declaração, defende que a criança tem o direito de se desenvolver de maneira normal, material e espiritual. O segundo considera que a criança que tem fome deve ser alimentada, a doente deve ser tratada, a 'retardada' deve ser encorajada, a órfã e abandonada devem ser abrigadas e protegidas. O terceiro princípio defende que a criança deve ser preparada para ganhar a vida e deve ser protegida contra qualquer 
tipo de exploração. Por fim, o quarto princípio geral destaca que a criança deve ser educada dentro do sentimento de que as suas melhores qualidades devem ser postas a serviço de seus irmãos.

Outros instrumentos e ações em defesa da criança foram empreendidas.

Figura 2: Mapeamento de ações e instrumentos legais em favor da criança

\begin{tabular}{|c|l|}
\hline 1946 & $\begin{array}{l}\text { UNICEF, pós Segunda Guerra recebe apoio do Fundo Internacional de Ajuda } \\
\text { Emergencial a Infância necessitada (ONU - Organização das Nações Unidas) }\end{array}$ \\
\hline 1959 & $\begin{array}{l}\text { Declaração Universal dos Direitos da Criança: Universidade, Objetividade e } \\
\text { Igualdade como princípios básicos }\end{array}$ \\
\hline 1989 & $\begin{array}{l}\text { Convenção das Nações Unidas sobre os Direitos da Criança (direito a um melhor } \\
\text { padrão de vida, define que criança e adolescente é a pessoa que vai até os 18 anos } \\
\text { de idade, ter nome e nacionalidade etc) }\end{array}$ \\
\hline $\mathbf{1 9 9 0}$ & $\begin{array}{l}\text { Foram incorporados à Convenção de 1989 atenção à criança ou adolescente em } \\
\text { conflito com a lei; direito ao desenvolvimento integral; apoio à família; e esforço } \\
\text { pela distribuição de recursos mais equitativos }\end{array}$ \\
\hline debate intenso & $\begin{array}{l}\text { Criação da Frente Parlamentar Suprapartidária. Governo e sociedade garantiram, } \\
\text { em 1988, em três artigos da Constituição - 227, 228 e 229 -, um "lugar" para a } \\
\text { criança na história, a partir da lei }\end{array}$ \\
\hline $\mathbf{1 9 9 0}$ & $\begin{array}{l}\text { ECA, assinado em 1990, que revogou o Código de Menores, bem como a lei que } \\
\text { criou a Fundação Nacional do Bem-estar do Menor (FUNABEM). 1991, foi } \\
\text { criado o Conselho Nacional dos Direitos da Criança e do Adolescente } \\
\text { (CONANDA), responsável pela implementação do ECA. 1993, o Programa } \\
\text { Nacional de Atenção Integral à Criança e Adolescente (PRONAICA) foi criado } \\
\text { pelo Ministério da Educação }\end{array}$ \\
\hline
\end{tabular}

Fonte: Figura elaborada pela autora.

Didonet, no documento da Unesco intitulado 'Educação infantil no Brasil: primeira etapa da educação básica' (2011, p.17), dá destaque ao direito da criança a Educação Infantil considerando que a integralidade do desenvolvimento infantil apresenta 3 etapas:

[...] - do começo das iniciativas de atendimento à criança até a redemocratização do país (1875-1985); • período da Assembleia Nacional Constituinte, promulgação da Constituição Federal e elaboração das leis que a regulamentam na área dos direitos da criança (1986-1996); • formulação de diretrizes, políticas, planos e programas que objetivam a realização dos direitos da criança (1996 até os dias atuais). O primeiro período caracteriza-se pela diversidade de iniciativas em diferentes setores, com tentativas de atendimento integral da criança; o segundo, pela intensa e diversa participação social na construção do arcabouço jurídico que acolhe a criança como cidadã, sujeito de direitos; e o período atual, em que o Estado focaliza a criança como sujeito de políticas públicas e se retoma a mobilização da sociedade, por meio de suas organizações representativas.

Vale ressaltar que a Constituição Federal de 1988, em muito contribuiu para a construção dessa atual concepção de criança como sujeito de direitos, pois a mesma inclui a criança em contexto amplo de cidadania, sistematizando novas relações entre ela e o Estado. A constituição dá destaque para a criação desse 'novo paradigma', da criança como sujeito de direitos, incluindo o seu direito à educação Infantil, a partir de dispositivos legais importantes, conforme segue defendendo Didonet et al (2011, p. 30) 
Seus direitos são citados no artigo 227 da Constituição. Ela é vista, portanto, na integralidade de sua pessoa. b) Seus direitos devem ser garantidos com absoluta prioridade pela família, pela sociedade e pelo Estado. c) Abrangência: “[...] direito à vida, à saúde, à alimentação, à educação, ao lazer, à profissionalização, à cultura, à dignidade, ao respeito, à liberdade e à convivência familiar e comunitária", e direito de estar "[...] a salvo de toda forma de negligência, discriminação, exploração, violência, crueldade e opressão" [...] O direito da criança à educação infantil é solidário ao direito dos pais trabalhadores (não mais apenas da mulher), à educação de seus filhos e dependentes (além dos filhos biológicos, são incluídos os adotivos ou que estão sob sua guarda), durante todo o período que antecede a escolarização compulsória, isto é, do nascimento aos 6 anos de idade (não mais apenas no período da amamentação, como preconizava a CLT). e) A creche, com tudo o que ela comporta de cuidado para crianças de 0 a 3 anos, adquire um novo lugar: a educação. A Constituição coloca-a no capítulo da Educação. Isso significa que o cuidado que envolve a atenção às crianças mais novas é uma tarefa e uma atividade educativa. [...] O Estado tem o dever de garantir a educação infantil às crianças de até 5 anos em creches e pré-escolas (art. 208, IV). A Emenda Constitucional no 53/ 2006 baixou de 6 para 5 anos o período da educação infantil porque, em 2005, o início do ensino fundamental obrigatório foi estabelecido aos 6 anos.

$\mathrm{Na}$ sequência de estudos do grupo focal, pós aprofundamento sobre trajetória história dos direitos da criança, bem como reflexão acerca dos mitos que dificultam a implantação do ECA nas escolas de Educação Infantil (sobre os mitos vide material do III Seminário Luso-brasileiro de educação de Infância, 2017), os participantes consideraram que o Brasil tem uma base legal muito interessante que contribui para a construção dessa categoria de estudos na qual a 'criança é sujeito de direitos', porém a trajetória é longa para que na prática, na rotina e na formação de professores de crianças pequenas essa concepção se efetive, bem como na sociedade de forma geral.

Quanto a essa conclusão, foi lançada a seguinte questão: Que caminhos a educação Infantil deve adotar para efetivar os direitos das crianças? Questão que gerou os seguintes posicionamentos:

Professor H: Alguns direitos devem começar na escola. A escola deve promover um trabalho de conscientização e informação aos pais e buscar lutar diante do Estado.

Professor G: Contribuir para que o Estatuto seja cumprido de forma que se evidencie esses direitos. O direito a educação de qualidade, a escola tem que cumprir sen objetivo de aprendizagem de modo que atribua a criança o direito a educação, ter criatividade $e$ autonomia.

Professor J: Acredito que os caminhos a serem traçados para a efetivacão dos direitos infantis, devem partir do respeito que devemos ter com as crianças, o olhar sensivel às suas necessidades e a valorização como sujeito.

Professor M: O primeiro é o da pesquisa de métodos que garantam ao profissional arcabouco que fundamente a sua prática. O educador precisa compreender os direitos da criança garantidos por lei, mas também compreender que nós somos seres sociais e históricos, respeitando assim cada um de seus processos individuais.

Professor N: Que as leis sejam efetivas, que tenha fiscalização [...] porque a maioria delas não passam do papel ou só favorecem uma parte da populaşão. valoriz̧ar a educação como a etapa mais importante da vida, valorizar os profissionais da educaşão.

Uma outra temática relacional recorrente no diálogo do curso, diz respeito à incorporação da cultura de paz na educação infantil, esta cultura que surge da relação adulto e criança e que contribuirá com o fortalecimento da criança como sujeito de direitos. 
A obra 'Paz e Educação Infantil' de Marques e Wachs (2015) é um significativo termômetro relativo a importância dessa abordagem contemporânea na Educação Infantil. A mesma coloca as crianças no debate direto com o adulto sobre a vida social, considerando que são sujeitos e elaboradoras do mundo e por isso têm o direito de receber do adulto as informações necessárias para a sua participação efetiva na sociedade, o adulto não deve 'esconder nada' da criança

[...] Aquilo que é vivido pelas crianças na Educação Infantil tende a deixar marcas em suas ideias e sentimentos, em suas ações e interações, contribuindo para que assumam ou não compromisso com a mudança social. os adultos têm papel relevante nas experiências vividas por elas no ambiente escolar. A respeito da abordagem de temas realistas existenciais com as crianças, André de Carvalho (apud Brandão, 1977, p.2) aponta que '[...]a criança não pode ser murada; não adianta querer preservá-la, [...], erigila em último reduto. [...] é preciso não esconder nada, mas mostrar que apesar de tudo, este mundo pode e deve ser reconstruído, exatamente por esta criança participante'.

É papel dos adultos, em especial do professor, comprometer-se com essa Infância, utilizando-se da cultura da paz. Nesse sentido, a adoção dessa perspectiva amplamente debatida atualmente em contexto nacional e internacional (RAYO 2004, JARES 2002, GUIMARÃES 2005) e Organizações de Defesa dos Direitos Humanos chamada Educaşão para a Paz é chave essencial para a organização de relações sociais fundadas no respeito e defesa dos Direitos Humanos e dos Direitos das crianças de forma específica. Relações fundadas no respeito aos direitos para o desenvolvimento e dignidade plenos das pessoas, especialmente da Infância Brasileira.

Ampliando os tímidos esforços que vem sendo empreendidos por Ongs, Instituições de Atenção à Infância, Especialistas e Educadores Críticos, por defender a Cultura da Paz, esta que situa os direitos humanos como caminho de aumento do nível de crescimento social centrado nas pessoas, não no capital e nos processos de globalização da economia e muito menos no exercício crescente da violência como resolução dos problemas e conflitos sociais.

A Educação para a paz prevê aprendizagens significativas e solidárias, faz crítica suficiente para possibilitar a construção de novas consciências e existências que sejam preocupadas, por exemplo, com a situação da criança no século XXI, que garanta um pensamento aberto para provocar transformações através da participação cidadã e democrática.

A Cultura da Paz na Educação, coloca a criança e a Infância na centralidade das discussões, bem como reconhece que há um conjunto de problemas sérios em nível mundial que devem ser imediatamente pensados para a sobrevivência de todos e de todas (RAYO, 1998). São problemas que põem em risco os próprios ideais da humanidade e os grupos sociais que a compõem (com destaque para as crianças): a violência, a negação de direitos, o aumento da pobreza, a destruição ambiental, a escravidão, a imigração, a fome, a ocupação de territórios, a questão dos refugiados, a saúde e vida plena em geral, aos conflitos religiosos e étnicos, o abandono e exploração da infância, a dissolução das famílias como base de apoio e que afetam a criança, enfim, é preciso pensar o lugar da infância no mundo dominado pela globalização da economia e pelas políticas neoliberais.

Para superação de visões 'ingênuas' de Educação Infantil, é preciso focar nesses temas para além do didatismo pedagógico relativo à vida das crianças. Em conversa com colega que trabalha em 
Educação Infantil na França e que recebe crianças refugiadas, a mesma citou as alegrias bem como as dificuldades de desenvolver ação pedagógica respeitando oito línguas (as faladas pelas crianças refugiadas, oriundas de várias países). Porém, esta mesma professora tem a clareza que aquelas crianças são dotadas de direitos e merecem educação de qualidade ainda que não estejam em seus países de origem.

A Cultura e a Educação para a Paz implica em relações mais justas entre adultos e crianças, reconhece a igualdade dos direitos de todas as pessoas, povos e culturas que gozam dos recursos e bens produzidos, sejam materiais, humanos e/ou espirituais. Segundo Rayo (1998), paz é sinônimo de Direitos Humanos e Liberdades Fundamentais garantidos a todos.

Santos (2006) afirma que chefes de Estados e Governos devem assumir compromissos no âmbito da garantia de direitos, como bem defende a Declaração de Copenhague: proteção dos direitos das crianças e jovens porque a vida da Infância, em especial a que sofre, é termômetro que mede a má organização do mundo e os problemas sociais de cada sociedade.

A educação infantil, e suas demais necessidades básicas, compõem as metas para o desenvolvimento humano no século XXI e está na agenda dos direitos humanos que devem ser garantidos também no Brasil.

O aprofundamento de uma prática pedagógica na Educação Infantil voltada para a garantia e desenvolvimento de aprendizagens compartilhadas entre adultos e crianças, de vocação solidária e preocupada com temas que não foram tradicionalmente reconhecidos, a saber a criança como sujeito de direitos, especialmente no Brasil, se delineia como abordagem do século e quicá do milênio.

\section{Palavras finais}

As reflexões 'costuradas' a partir desta pesquisa nos fez concluir que o Estatuto da Criança e do Adolescente não foi ainda implantando efetivamente nas instituições infantis no Brasil, nota-se pelas precárias condições materiais e formativas a que estão submetidas as crianças, bem como há ainda muito que ser feito para que a criança seja de fato considerada 'sujeito de direitos', esta que é uma categoria a ser largamente construída, principalmente pelos adultos que lidam e transitam pelo universo infantil, ou seja professores e demais profissionais da educação.

Além disso, concluímos que é preciso o reconhecimento dos direitos humanos e da educação para a paz como temas de relevância para a educação infantil e para a construção da categoria 'Criança como Sujeito de Direitos'.

Por fim, considera-se que, para a construção e validade de uma Cultura e a Educação para a Paz na Educação Infantil, há de se empreender e garantir relações mais justas entre adultos e crianças e o reconhecimento da igualdade dos direitos de todos e todas com foco especial nos direitos das crianças. 


\section{Referências}

ANDRÉ, Marli. Etnografia da prática escolar. São Paulo: Papirus, 2005.

Brasil, 1979. Lei 6697 de 10 de outubro de 1979. In:

https://presrepublica.jusbrasil.com.br/legislacao/128333/lei-6697-79 (Acesso: 15/10/2016).

Brasil. Ministério da Educação. Secretaria de Educação Básica. Diretrizes curriculares nacionais para a educação infantil / Secretaria de Educação Básica. - Brasília : MEC, SEB, 2010.

Brasil. Ministério da Educação. Secretaria de Educação Básica. Referencial curricular nacional para a educação infantil / Ministério da Educação e do Desporto, Secretaria de Educação Fundamental. Brasília: MEC/SEF, 1998.

Brasil. (1990). Estatuto da Criança e do Adolescente. Lei 8.069, de 13 de julho de 1990. Brasília.

DIDONET, Vital et al. Educação infantil no Brasil: primeira etapa da educação básica. Brasília: UNESCO, Ministério da Educação/Secretaria de Educação Básica, Fundação Orsa, 2011.

GUIMARÃES, Marcelo R (2005). Educação para a Paz: Sentidos e dilemas. Caxias do Sul, RS: Educs.

JARES, Xésus R (2002). Educação para a paz: Sua teoria e sua prática. Tradução Fátima Murad. Porto Alegre: Artmed.

LUCY, Viviane Moretto da Silva et al. Educação Infantil: Da visão assistencialista à educacional. Interfaces da Educ., Paranaíba, v.2, n.6, p.86-94, 2012. ISSN2177-769.

MARCÍLIO, Maria Luiza. A lenta construção dos direitos da criança brasileira. São Paulo: Revista da USP, 1998.

NUCCI, Guilherme. Estatuto da criança e do adolescente comentado. Brasilia: Editora Forense, 2014.

MARQUES, Circe Mara e WACHS, Manfredo Carlos. Paz e Educação Infantil. Escutando a voz das crianças. São Paulo: Paulinas, 2015.

RAYO, José Tuvilla (2004). Educação em Direitos Humanos. Rumo a uma perspectiva Global.Porto Alegre: Artmed. 
ROCHA, Ruth. Os direitos das crianças segundo Ruth Rocha. 2 ed. São Paulo: Salamandra, 2014.

SANTOS, Ana Katia Alves dos. Infância Afrodescendente: Epistemologia crítica no ensino fundamental. Salvador: Edufba, 2006.

SIROTA, Régine. Da Sociologia da Educação à Sociologia da Infância. Entrevista via Universidade Paris Decartes-Sorbonne. In: Atos de Pesquisa em Educação. PPGE/ME FURB. V. 6. N. 3. p. 562571.set/dez 2011 .

Emergência de uma sociologia da infância: evolução do objeto e do olhar. In: Cadernos de Pesquisa. São Paulo, no 112, março, 2001 P 7-31.

Recebido em: 10/08/2017

Aprovado em: 26/11/2017 